\title{
6
}

\section{On the Right to Science As a Cultural Human Right}

\author{
Farida Shaheed and Andrew Mazibrada*
}

\subsection{INTRODUCTION}

What is science, and what role should it play in the future mediation of our global society? Any discussion of the human right to science ought to begin by trying to answer those two foundational questions. As counterintuitive as it may seem in an age dominated by technology, consensus on how those questions might be answered has thus far proved elusive. More difficult still is elucidating the position of science within a framework of human rights.

It may seem strange at first to talk of science as mediation. Yet science pervades complex societal spaces in areas beyond innovation, technology, and access to their benefits. Science and culture intertwine and overlap, and contribute symbiotically to intellectual creativity and expression in complicated ways. These are best framed and analysed as mediations of complex, bidirectional relationships. This, we believe, offers more invaluable insights into the future role of science in our society.

\subsection{SCIENCE AS GLOBAL KNOWLEDGE AND A PUBLIC GOOD}

Several core themes must be appreciated before these questions can be addressed in the modern context, as global interconnectedness, human rights, and cultures have evolved in tandem with science and technology.

Science and culture are symbiotic. Freedom to engage in creativity is central to both and, perhaps more importantly, each informs and shapes the other in crucial ways. General Comment 25, published in April 2020, reinforces this view:

Cultural life is an "inclusive concept encompassing all manifestations of human existence." Cultural life is therefore larger than science as it includes other aspects of human existence; it is however reasonable to include scientific activity in cultural

* This chapter had its origins in an interview conducted on March 5, 2020 between Farida Shaheed, Helle Porsdam, and Sebastian Porsdam-Mann whom the authors would like to thank for their insightful questions and contributions. 
life. Thus, the right of everyone to take part in cultural life includes the right of every person to take part in scientific progress and in decisions concerning its direction. ${ }^{1}$

The indelible relationship between science and culture is also reflected in the intentions of the drafters of the Universal Declaration on Human Rights (UDHR). There was, at the time of its drafting shortly after World War II, an intention to promote universal access to both science and culture. Lea Bishop, to whom scholarship in this area owes a great debt, has also suggested that, when the UDHR was being signed, the United Nations had come to envisage the sharing of scientific and cultural knowledge as something that could unite an international community. ${ }^{2}$ It would be a "task in common" that would bring people together, uniting them with a common journey of discovery. This would, in turn, help "promote cross-cultural understandings" and "yield a more secure world."3 Understanding science as contributing to knowledge is holistic. Knowledge production is the intellectual and creative activity of engaging with the world around us, which necessitates translating the product of that activity into different forms, only one of which is what we traditionally see as science. Others include art, literature, philosophy, and the social sciences.

For this collaborative intent to truly succeed, knowledge must itself be seen as a public good, there to be shared across the world without exception.

It is not just a question of having access to what people produce, but to the whole process of creativity. It is the ability to fully explore the whole of one's own potential in all its diverse aspects, to benefit from the creativity of others, and the protection of the moral and material interests that result - as the Covenant stipulates, those which emanate from any scientific, literary, or artistic production.

\subsection{PARTICIPATION IN SCIENCE, CULTURE, AND RIGHTS DisCOURSES}

Human development is about participation, necessitating freedom to fully and actively contribute, and the right to science must also be interpreted from that perspective. ${ }^{4}$ It cannot be just about access to the benefits, or the products, of scientific advances. Discourses about access to science are too often framed as exclusively concerning access to the end product, whether an idea or invention.

1 Committee on Economic, Social and Cultural Rights, General Comment No. 25 (2020) on Science and economic, social and cultural rights Art. 15.1.b, 15.2, 15.3 and 15.4, (E/C.12/GC/25, 7 April 2020), para. 10

2 Lea Bishop, "The Right to Science and Culture" (2010) Wisconsin Law Review 121, 141. Also see generally Lea Bishop, "The Right to Science: Ensuring that Everyone Benefits from Scientific and Technological Progress” (2014) 4 European Journal of Human Rights 411.

3 Bishop, "The Right to Science and Culture," ibid.

4 There is a great deal to be gained from a historical analysis of the way in which the right to science evolved, touched on by the chapters contributed to this volume by Aurora Plomer (Chapter 3) and Cesar Romano (Chapter 2). 
Access also includes the participation of people affected by science, meaning everyone worldwide, as confirmed in General Comment $25 .{ }^{5}$

Participation includes the freedom to experiment and fully explore one's own creative potential, and informed engagement in the political decision-making processes concerning research prioritization. Participation in ethically significant and politically polarized areas and contexts, such as artificial intelligence and the modification of the human germline, raise several tensions and necessitate a reconceptualization of science's role in modern society. That role cannot be understood outside a cultural context.

One way of conceptualizing the influence science has on rights is through the emerging technologies it has created, and more specifically through of the problem of meaningful consent. This allows us to understand the role science will play in global society in several linked ways. Firstly, in scientific research, consent is the ethical ground zero. This fundamental principle sheds light on two related tensions explored in this chapter. The first concerns the tensions between publicly and privately funded research. The second considers what makes consent meaningful and explores what that means beyond the research context, into the application of such research.

Facebook has conducted at least two now well-known experiments in social manipulation. ${ }^{6}$ No consent was obtained from participants in advance. Public outrage seemed not to deter Facebook at all. The second study, published in a prestigious scientific journal, the Proceedings of the National Academy of Sciences (PNAS), "manipulated the extent to which [689,003] people ... were exposed to emotional expressions in their News Feed." ${ }^{7}$ Most interesting, however, was the debate between scientific professionals about the role of consent. On July 3 , 2014, Inder M. Verma, the then PNAS editor-in-chief, published an "Editorial Note of Concern" responding to concerns "raised about the principles of informed consent and opportunity to opt out in connection with the research in this paper," and defending publication. ${ }^{8}$

5 Committee on Economic, Social and Cultural Rights, General comment No. 25 (2020) on Science and economic, social and cultural rights Art. 15.1.b, 15.2, 15.3 and 15.4, (n 2), para. 10.

6 Robert M. Bond, Christopher J. Fariss, Jason J. Jones, Adam D. I. Kramer, Cameron Marlow, Jaime E. Settle and James H. Fowler, "A 61-Million-Person Experiment in Social Influence and Political Mobilization" (2012) 489 Nature 295. In a controlled, randomized study conducted during the 2010 US congressional elections, Facebook researchers manipulated the content of "political mobilization messages" in the news feeds of nearly sixty-one million Facebook users while also establishing a control group. The results showed that "the messages directly influenced political self-expression, information seeking and real-world voting behaviour of millions of people"; Adam D. I. Kramer, Jamie E. Guillory, and Jeffrey T. Hancock, "Experimental Evidence of Massive-Scale Emotional Contagion Through Social Networks" (2014) 111(24) Proceedings of the National Academy of Sciences 8788.

7 Kramer, Guillory, and Hancock (n. 7).

8 Editorial Expression of Concern: Experimental evidence of massive-scale emotional contagion through social networks, PNAS July 22, 2014111 (29) 10779; first published July 3, 2014 https://doi.org/10 $.1073 /$ pnas.1412469111. This response remains attached to the paper: "Adherence to the Common Rule is PNAS policy, but as a private company Facebook was under no obligation to conform to the 
A central issue in ethical discourses concerning emerging technology, and information and communication technology (ICT) in particular, regards Big Data: the collection, storage, and analyses of massive databases. The issue of consent is complex and extends beyond scientific research to use of the resulting products, for example in the Terms of Service offered to users of Internet platforms. Recent research demonstrates that reading all the agreements attached to the various applications we regularly use would take something in the order of weeks. ${ }^{9}$ Nevertheless, we just click and go on. There is no interaction and certainly we are not informed in any meaningful way. There are few alternatives: in a recent US Supreme Court case, the view was expressed that foreclosing "access to social media altogether is to prevent the user from engaging in the legitimate exercise of [free speech] rights. ${ }^{" 10}$

The lack of genuine consent is of concern where platforms extract user data and then profile those users for marketing and manipulation. ${ }^{11}$ They do so in a way that is opaque, not clearly understood, and unaccountable to a democratically elected

provisions of the Common Rule when it collected the data used by the authors, and the Common Rule does not preclude their use of the data. Based on the information provided by the authors, PNAS editors deemed it appropriate to publish the paper. It is nevertheless a matter of concern that the collection of the data by Facebook may have involved practices that were not fully consistent with the principles of obtaining informed consent and allowing participants to opt out." The study's editor, Susan Fiske from Princeton University's Department of Psychology, reportedly told The Atlantic that as a private company, Facebook did not have to conform to the legal standards for scientific research required of federally-funded researchers: Adrienne Lafrance, "Even the Editor of Facebook's Mood Study Thought It Was Creepy" The Atlantic, June 28, 2014, (www.theatlantic.com/technology/arch ive/2014/o6/even-the-editor-of-facebooks-mood-study-thought-it-was-creepy/373649/). The legal standards are known as the Common Rule. It is a rule of ethics in biomedical and behavior research involving human subjects ratified in 1981 and later significantly revised in 2018. The Common Rule sets out procedures for informed consent and transparency generally, and protections for certain vulnerable subjects. It is administered by Institutional Review Boards, appointed within every research institution, the members of which must be "sufficiently qualified through the experience and expertise of its members (professional competence), and the diversity of its members, including race, gender, and cultural backgrounds and sensitivity to such issues as community attitudes, to promote respect for its advice and counsel in safeguarding the rights and welfare of human subjects." "Protection of Human Subjects", Code for Federal Regulations, Title 45, (2018), Part 46.107(a).

9 See for example Aleecia M. McDonald, Lorrie Faith Cranor, "The Cost of Reading Privacy Policies" (2008) 4(3) I/S: A Journal of Law and Policy for the Information Society 543 (estimating that if an individual actually read privacy policies, this would require 244 hours per year) and more generally on consent in terms of privacy considerations, Daniel J. Solove, "Privacy Self-Management and the Consent Dilemma" (2013) 126 Harv. L. Rev. 1880.

10 Packingham v. North Carolina 137 S. Ct. 1730 (2017) (describing internet platform and social media services as a "modern public square," Justice Kennedy acknowledged their essential nature to speech, calling them "perhaps the most powerful mechanisms available to a private citizen to make his or her voice heard"). See also Kate Klonick, "The New Governors: The People, Rules, and Processes Governing Online Speech” (2018) 131 Harv. L. Rev. 1598.

"Daniel Susser, Beate Roessler, and Helen Nissenbaum, "Online Manipulation: Hidden Influences in a Digital World” (2019) 4 Geo. L. Tech. Rev. 1; Karen Yeung “Hypernudge': Big Data As a Mode of Regulation by Design" (2017) 20(1) Information, Communication \& Society 118; Shoshana Zuboff, "Big Other: Surveillance Capitalism and the Prospects of an Information Civilization" (2015) 30 Journal of Information Technology 75 . 
body. ${ }^{12}$ Users are simply not aware of how much data is being collected from their use of these technologies and to what use it has been or will be put. The long-term effects on the well-being of both individuals and communities is unknown to us, but is likely to be considerable. It will reshape cultures in an undemocratic way.

\subsection{DATA NEUTRALITY}

There are frameworks that address the way commercial entities should act in such circumstances: the UN Guiding Principles on Business and Human Rights, ${ }^{13}$ for instance, or the Montréal Declaration on the Responsible Use of Artificial Intelligence. ${ }^{14}$ These are areas in which UN Special rapporteurs are particularly active, drafting instruments and advice for the governing of that surveillance in order to protect our rights to free speech and privacy. ${ }^{15}$ However, governing these sprawling, global commercial entities is challenging not only because of the transnational nature of their use and influence, but also because many are US-based organizations.

There is particular emphasis in the US context on protecting free speech and the free market, sometimes at the expense of protecting individual and collective rights. ${ }^{16}$ These technologies and their derivatives, that is, AI and Big Data algorithms, demonstrate that science is fundamentally intertwined with culture and directly impacts how culture evolves. This has significant implications for the right to science and its relationship with other rights.

From a privacy perspective, for example, seeking the deletion of such data is challenging. Europe has recently adopted a different approach to the USA under the GDPR. ${ }^{17}$ However, there is little consensus among scholars as to whether GDPR

12 See generally Shoshana Zuboff, The Age of Surveillance Capitalism: The Fight for a Human Future at the New Frontier of Power (New York: Public Affairs, 2019) and Julie E. Cohen, Between Truth and Power: The Legal Constructions of Informational Capitalism (Oxford: Oxford University Press, 2019).

13 United Nations, Guiding principles on business and human rights: Implementing the United Nations "Protect, Respect and Remedy" framework (United Nations, Office of the High Commissioner for Human Rights, 2011).

14 www.montrealdeclaration-responsibleai.com/.

15 See, for example, the work of David Kaye, Special Rapporteur on the promotion and protection of the right to freedom of opinion and expression, who has authored several reports on freedom of expression in the information and digital age, covering topics such as online hate speech $(\mathrm{A} / 74 / 486$, October 9 , 2019), Artificial Intelligence technologies and implications for the information environment $(\mathrm{A} / 73 /$ 348, August 29, 2018), online content regulation (A/HRC/38/35, April 6, 2018) and the role of digital access providers (A/HRC/35/22, March 30, 2017). David Kaye, Speech Police: The Global Struggle to Govern the Internet (Columbia Global Reports, 2019).

16 See, for example, Julie E. Cohen, “The Zombie First Amendment” (2015) 56 Wm. E Mary L. Rev. 1119 and Jack M. Balkin, "Free Speech in the Algorithmic Society: Big Data, Private Governance, and New School Speech Regulation" (2018) 51 UCD L. Rev. 1149.

17 Regulation (EU) 2016/679 of the European Parliament and of the Council of 27 April 2016 on the protection of natural persons with regard to the processing of personal data and on the free movement of such data, and repealing Directive 95/46/EC [2016] OJ Li19/1 (GDPR). 
will be effective. ${ }^{18}$ We are faced with tools for our everyday lives that develop so rapidly that governance structures and legislative measures cannot hope to keep up. Fines imposed under regimes like GDPR are easily written off, for example as tax deductible expenses. To huge, wealthy platforms, such fines are merely another cost of doing business. This US emphasis on innovation highlights the tension between access to the benefits of science and its advancements, and intellectual property rights and innovation. There is a balance to be struck between these elements, but it must not be at the expense of other rights or natural justice.

There's a tendency to presume that data is neutral. It is not. Algorithms predict based on incomplete data in all kinds of areas, and their use will likely increase with time. There is wide consensus among scholars that this will exacerbate existing problems of discrimination. ${ }^{19}$ This manifests in several ways. Firstly, those currently at the margins of society are also the furthest from access to such technology, exacerbating their inequality. Secondly, algorithms reflect the biases of their creators and training data: their use may further perpetuate societal biases in opaque ways. Further, exclusion leads to skewed or value-laden data. ${ }^{20}$ For instance, if marginalized communities are excluded in some way or another from using various technologies, their data cannot be considered by the algorithms that otherwise govern them. People in authoritarian countries will experience this effect even more dramatically. Dissidents whose voices are violently silenced will have no place in this collected mega data, and it is voices like these, diverse and independent voices, whose data would reflect the true texture of the world we inhabit. Often it is in the margins where change begins, where debate and insight are catalysts for new awareness. There is, for instance, widely expressed concern regarding increased surveillance through smartphone technology as a consequence of the global emergency engendered by the COVID-19 pandemic and the state of that surveillance once the state of emergency has ended. ${ }^{21}$

There is, we suggest, no such thing as neutral data just as there is no such thing as neutral research. When investigative research parameters are set out, and questions

18 See, for example, Tal Z. Zarsky, "Incompatible: The GDPR in the Age of Big Data" (2017) 47 Seton Hall L. Rev. 995; Lilian Edwards and Michael Veale, "Slave to the Algorithm: Why a Right to an Explanation Is Probably Not the Remedy You Are Looking for" (2017-2018) 16 Duke L. E Tech. Rev. 18; and Margot E. Kaminski, “The Right to Explanation, Explained” (2019) 34 Berkeley Tech L.J. 189.

19 See for example, Frank Pasquale, The Black Box Society (Cambridge, MA: Harvard University Press, 2015); Cathy O'Neill, Weapons of Math Destruction (London: Penguin UK, 2017); Danielle Keats Citron and Frank Pasquale, "The Scored Society: Due Process for Automated Predictions" (2014) 89 Wash. L. Rev. 1; Sonia K. Katyal, "Private Accountability in the Age of Artificial Intelligence" (2019) 66 UCLA L. Rev. 54.

20 See, for example, Chapter 9 in this volume authored by Valerie Bradley on the effect of such algorithms on people with disabilities who, it might be argued, are too often left out of such discourses on discriminatory algorithms.

${ }^{21}$ Yuval Noah Harari, "The World After Coronavirus," The Financial Times, March 20, 2020; Natasha Singer and Choe Sang-Hun, "As Coronavirus Surveillance Escalates, Personal Privacy Plummets," The New York Times, published March 23, 2020, updated April 17, 2020 (www .nytimes.com/2020/03/23/technology/coronavirus-surveillance-tracking-privacy.html). 
framed, there is often a way of thinking about assumptions that can combine inherent and often subconscious prejudices. Culture and ideology affects the conduct even of good science. It is worth recalling General Comment 25: the expression, "to enjoy the benefits of scientific progress" is "not restricted to the material benefits or products of scientific advancement, but includes the development of the critical mind." ${ }^{22}$

In 2012, during the process of researching the special rapporteur's report for the $\mathrm{UN}$ on the right to science, the need of mobile phones for migrant women workers had become critical. For migrant workers to lose access to their phones - because they were taken from them by their employers - while alone and in unfamiliar parts of the world, in regions and cultures that might be alien to them, meant stripping them of access to any kind of support system. But now we see that telephones, in particular smart phones, also expose them to new kinds of risks - surveillance by private actors and by states, for different but no less potentially damaging reasons. There must always be a balance in terms of who has access to and use of such data, what it is ultimately used for, and what kind of informed consent has been obtained for those uses. Access must not be limited by income or background, and a realistic degree of privacy must always accompany access. When governments and organizations formulate policies and plans of data collection and use, we must acknowledge that it is potentially skewed in unpredictable ways and we must protect those who might be excluded or prejudiced as a consequence.

At a recent meeting on children's rights in the digital world, as part of the UN Committee on the Rights of the Child's endeavor to draft a General Comment, it was noted that the young see no difference between their online and offline lives. To them, it is simply one life. The UN takes the view that all the rights enjoyed offline, in the physical world, should also be enjoyed online, in cyberspace. That, we know, is not currently the reality. How we move from simply saying it should be this way, to ensuring those rights can be enjoyed in cyberspace, is one of the core challenges facing human rights in the digital era.

This raises an interesting question. For the moment, we can set scientific knowledge to one side and simply ask, what do we mean when we say "knowledge"? We live in a world where many young people believe that the only valid source of information and knowledge is mediated by ICT. But not all information of value is to be found online. This framing raises a key question on the nature of knowledge itself: Who populates knowledge? In developed states in the Global North, it is easy to forget that not everyone worldwide has the same access to ICT. Even in the digital age, we all contribute to what we consider our vast reservoir of knowledge, but not everyone does so in the same way. What we consider to be "knowledge" is distorted by the gap between those who have access to ICT, to digital means of populating knowledge, and those who do not. This affects how we define who is able to

22 Committee on Economic, Social and Cultural Rights, General Comment No. 25 (n. 2), para. 10. 
participate in the production of knowledge. Language is another example of how the Global North biases this framing of what constitutes knowledge. It plays a substantial role in who can actually access, contribute to, and therefore participate in knowledge production. It doesn't matter how advanced a community's ICT technology is, if a community is unable to communicate in the right languages, very often English, it will not be able to access and participate in knowledge production, or share their own knowledge. In time, artificial intelligence may contribute solutions to this problem by offering translation affordances, but we must not allow participation in, access to, and production of knowledge to be delayed while we wait.

To take this one stage further, knowledge access, production, and participation cannot become monopolized as a consequence of information technology architecture. Regulation and governance structures to avoid the kind of monopolistic practices we are seeing with major Internet platforms and ICT companies must be explored. This inevitably involves an interdisciplinary approach, utilizing tools from other disciplines outside of international human rights law, such as antitrust and competition law. It means reconceptualizing governance structures and approaches that can react more quickly to changes in the landscape of the digital world than can international human rights law. It means, we believe, integrating the norms of international human rights law into governance and regulation structures that do not necessarily need to rely on courts to ensure compliance with States' obligations and duties. Here again we see the inexorable convergence of science with culture, and of the right to science with cultural rights. This is the value of the initiation of the commons era of knowledge, of "open source," where anyone can contribute and make access open to all kinds of knowledge production and participation.

\subsection{THE TENSIONS BETWEEN PUBLICLY FUNDED AND PRIVATELY FUNDED RESEARCH}

Part of this monopoly-based concern centers on scientific research, and research in general, in public institutions that is being increasingly driven by private sector funding. This channeling of scientific interrogation in certain directions is deeply instrumentalist. And as public funding is regularly reduced across the board, even in Europe and wealthy industrialized states, funding for pure research is decreasing.

There is a perception that research must be focused on a product, the need for something tangible at its conclusion, rather than simply the advancement of scholarship and knowledge. This is especially the case when such research is privately funded. Consequently there is little space for purely theoretical research. So much of our early scientific research, whether in the natural and physical sciences, or the social, economic, and political sciences and philosophy, focused on thinking theoretically about the world and the universe it inhabits. There was no demand for a product at the end of that process. Now, the market drives the areas into which 
research is able to go, and how it explores those areas. It leaves little room for serendipity and, we believe, stifles the very creativity it seeks to foster.

Scientists conducting research are concerned with negotiating patents for whatever it is that they have, before publishing and making their research available to others. The importance of these issues was highlighted in the two 2015 follow-up reports to the UN the right to science, on Patent policy and the right to science and culture, ${ }^{23}$ and on Copyright policy and the right to science and culture ${ }^{24}$ and has taken on an even greater significance since. Access to the most prestigious scientific journals can be very difficult. Here, the digital age affords great potential for the sharing of knowledge, and for working with published scientific research. However, the essence of scientific work cannot be usurped by commercial incentives, or hindered by the need to copyright that work before sharing it and inviting its analysis. The core idea of science is that other researchers should be able to freely access, and thereby replicate, test and, if necessary, refute, the theories advanced. This is a process of thinking that requires onward momentum. We know that scientific hypotheses are not intended to be permanent, but should be continually tested. We must be able to communicate freely with each other to share new ideas. Intellectual property ideals cannot hinder that process. Framing the right to science in terms of cultural rights lends that notion added weight.

The other side of the public/private dynamic concerns work carried out in the public sector, but which is then transferred to the private sector. In this, we refer to public sector institutions receiving public funding for research that, on completion, leads to a product or outcome that profits the private sector.

The 2012 report to the UN on scientific progress and its applications and subsequent reports related to intellectual property laws ${ }^{25}$ were not received without comment, some of it strongly in opposition. The strongest opposition, unsurprisingly, came from highly developed countries and from country representatives in the World Intellectual Property Organization (WIPO). There were expressions of genuine concern about the unrest the report had created. ${ }^{26}$ This highlights a problem of background: the attendees at conferences and symposiums involving commercially or business oriented organizations like the World Trade Organization (WTO) and WIPO have dramatically different perspectives to those attending similar events focused on human rights issues. Private sector companies are rarely seated at tables

23 UNGA, "Report of the Special Rapporteur in the field of cultural rights on Patent policy and the right to science and culture" (2015) UN Doc. A/70/279. See also UNHRC, "Report of the Special Rapporteur in the field of cultural rights on The right to enjoy the benefits of scientific progress and its applications" (2012) UN Doc. A/HRC/2o/26.

24 UNHRC, "Report of the Special Rapporteur in the field of cultural rights on Copyright policy and the right to science and culture" (2014) UN Doc. A/HRC/28/57.

25 See above n. 24 and 25.

26 During the Interactive Dialogues around the first report on the right to scientific progress and its applications and subsequent reports in conversations at the time between one of the authors, Farida Shaheed, in her capacity as UN Special Rapporteur in the field of Cultural Rights, and members of the WIPO. 
with human rights scholars and practitioners. The outcome of this division, which has been obvious for some time, is the perception, particularly among scientific practitioners and researchers, that the courts favor market-oriented resolutions rather than those predicated on human rights. There are rare exceptions, of course, where intellectual property rights take a back seat to human rights, both individually but also collectively. Often, however, it is only as a result of public pressure and media attention. ${ }^{27}$

In the consultations and expert group meetings leading to the drafting of the Copyright and Patent reports, there was little in the way of engagement from the private sector. Only when the discussions concerned food-related rights was interest shown by a few private sector people engaged in the agricultural industry. It is hard to overstate the importance of such a diversity of expert opinion on an issue like foodrelated rights. The future of scientific research in this area is certainly dominated at present by genetically modified food chains. However, the same could be said of almost any area of emergent technology and scientific research: diversity of engagement is key.

In 2009 , the then special rapporteur on the right to food identified the increasing application of intellectual property regimes to plant varieties and seeds as a significant threat to food security, particularly for the poor. ${ }^{28}$ Intellectual property regimes focus exclusively on the commercial seed system, overlooking farmers' informal systems. National rules frequently prohibit even small farmers and public institutions from sharing, replanting, and improving seeds covered by patents and plant varieties. ${ }^{29}$ The "excessive protection of monopoly rights over genetic resources can stifle progress in the name of rewarding it." Such an approach "undermines the livelihoods of small farmers, traditional and not-for-profit crop innovation systems, agro-biodiversity as a global public good and the planetary food

27 In 2001, the United States agreed to bring to an end a trade dispute that had endangered supplies of cheaper drugs for HIV/Aids treatment in Brazil. Brazilian law allowed its government to grant compulsory licenses in special circumstances, waiving the patent rights of foreign companies in return for cheaper, locally produced, generic drugs which was the cornerstone of Brazil's then widely praised national Aids policy. The dispute had been seen as attempts by the USA and pharmaceutical multinationals to intimidate developing countries trying to obtain cheaper, wider access to essential medication. Brazil asserted the provision "was an important instrument available to the government, in particular in its efforts to increase access of the population to medicines and to combat diseases such as Aids." Peter Capella, "Brazil wins HIV drug concession from US," The Guardian, June 26, 2001 (www.theguardian.com/business/2001/jun/26/internationaleducationnews.medicalscience). In a similar case concerning Aids, amid public outrage thirty-nine pharmaceutical companies terminated legal proceedings in South Africa which had sought to stop the South African government importing cheaper generic medicines from abroad. See generally: William W. Fisher III and Cyrill P. Rigamonti, "The South Africa AIDS Controversy: A Case Study in Patent Law and Policy," The Law and Business of Patents, Harvard Business School (February 10, 2005) (https://cyber.harvard.edu /people/tfisher/South\%zoAfrica.pdf).

28 UNGA, "The right to food: Seed policies and the right to food: enhancing agrobiodiversity and encouraging innovation" (2009) UN Doc. A/64/170. See also UN Doc. A/7o/279 (n. 24), para. 52.

29 UNDP, "Global Commission on HIV and the law: risks, rights and health" (New York, 2012), recommendation 6.1. 
system as a whole." ${ }^{\circ}$ The critical point to recognize is that (at least) two parallel agricultural systems exist, and should continue to exist together and in harmony: the commercial seed system and the farmers' seeds (landraces) or informal systems. ${ }^{31}$ This is where the biodiversity emerges from.

Farmers working for generations with particular grains, and experts working in food technology, have valuable insight to offer. Wild seeds need to be mixed in with other varieties, for example, and the result then steeped in the chaotic complexity of nature, in order to draw out higher yielding seeds. Intellectual property regimes cause tension in other ways. Some new commercial patented seeds specifically block reproduction so cannot be replanted unless farmers pay again for the technology to release the reproductive part of the seed. Yet, and perhaps ironically, GMO patented seeds could not have been developed without the very same landraces seeds they threaten. Still commercial enterprises bring legal actions against farmers who harvest plants that include their patented seeds even if it is the wind that has carried them to adjacent fields.

Similar experiences can be gleaned from the perspective of indigenous peoples and small, local communities. The Small Island Developing States, for example, particularly those in the Pacific region, who do not consider themselves "indigenous" in the way developed States have tended to label them, possess considerable traditional knowledge, but they hold it communally. In such communities, knowledge is considered a common good. There are no individualized rights of property. When we consider the concept of moral and material interests of the author, for example, they respond that they are the collective authors, and the collective holders, of that knowledge. They are also its stewards and, as such, it is passed down from generation to generation.

Clearly, intellectual property law clashes violently with this normative system because it rejects the notion that such knowledge could be owned by any one individual or corporate entity. However, where such indigenous knowledge has been retained, cultivated, and improved over many generations, and in a way that is directly influenced by and sympathetic to the particular conditions of the region, it often becomes valuable to Global North commercial entities. In a situation where such intellectual property rights are simply unknown to such communities, it is easy to appropriate that knowledge for commercial purposes without the kind of compensation or recognition that would attach to researchers from the developed world doing similar work. Such appropriation has become widespread and is known as biopiracy, or in terms that are less politically charged, bioprospecting. ${ }^{32}$ The neem

30 UN Doc. A/70/279 (n 24), para. 52.

31 Olivier De Schutter, "The Right of Everyone to Enjoy the Benefits of Scientific Progress and the Right to Food: From Conflict to Complementarity" (2011) 33(2) Human Rights Quarterly 304.

32 See, for example, Janna Rose, "Biopiracy: When Indigenous Knowledge Is Patented for Profit', The Conversation, March 8, 2016 (https://theconversation.com/biopiracy-when-indigenous-knowledge-ispatented-for-profit-55589) who also links this practice to "scientific colonialism." 
tree case, ${ }^{33}$ which concluded a decade of litigation in 2005, provides a stark example of traditional knowledge becoming the subject of a prolonged patent battle and the tensions between different normative approaches in patent systems. It also offers a potential way forward to protect traditional knowledge. In the United States, prior knowledge or use which would deny a patent was recognized only if previously published in a printed publication ${ }^{34}$ - not, for example, if it had been passed down through generations of oral tradition. The European Patent Office (EPO), who had initially granted a patent to develop antifungal products to the US Department of Agriculture and multinational WR Grace in 1995, eventually agreed that the neem had actually been in use in India for a very long time. ${ }^{35}$ Since that case, India has bought about the cancellation or withdrawal of numerous patent applications relating to traditionally known medicinal formulations. Its Traditional Knowledge Digital Library (TKDL), a database containing millions of pages of formatted information on more than two million medicinal formulations in multiple languages, "bridges the linguistic gap between traditional knowledge expressed in languages such as Sanskrit, Arabic, Persian, Urdu and Tamil, and those used by patent examiners of major IP offices." 36

If unchecked, privately funded research and intellectual property law can act to enclose ${ }^{37}$ the products of creativity and access to knowledge, whether that research arises out of traditional scientific practices or the exploitation of indigenous or traditional knowledge..$^{8}$ As General Comment 25 observes:

Local, traditional and indigenous knowledge, especially regarding nature, species (flora, fauna, seeds) and their properties, are precious and has an important role to play in the global scientific dialogue. States must take measures to protect such knowledge, through different means, including special regimes of intellectual

$33 \mathrm{~T}$ o416/o1 (Method for controlling fungi on plants/THERMO TRILOGY CORPORATION) of 8.3.2005, ECLI:EP:BA:2005:To41601.20050308 (www.epo.org/law-practice/case-law-appeals/recent/ to10416eur.html).

34 Pre-AIA 35 U.S.C. 102, Conditions for patentability; novelty and loss of right to patent (www.uspto.gov /web/offices/pac/mpep/szizz.html).

35 Ibid. See also Ulrike Hellerer and K. S. Jarayaman, "Greens Persuade Europe to Revoke Patent on Neem Tree" (2000) 405 Nature 266-267 (https://doi.org/10.1038/35012778) (concerning the first instance decision in 2000) and "India wins landmark patent battle" BBC News, March 9, 2005 (http://news.bbc.co.uk/2/hi/science/nature/4333627.stm) and Vandana Shiva, "The Neem Tree A Case History of Biopiracy' (https://twn.my/title/pir-ch.htm).

${ }_{3}^{6}$ V. K. Gupta, 'Protecting India’s Traditional Knowledge' WIPO Magazine, June 2011 (www.wipo.int /wipo_magazine/en/2011/oz/article_oooz.html\#2).

37 On the concept of enclosure used this way see Cohen, Between Truth and Power: The Legal Constructions of Informational Capitalism (n. 13) 8-12, 15-33.

$3^{8}$ There are various measures being taken to protect these kinds of interests and prevent biopiracy. See for example the WIPO definition of "traditional knowledge" from the Intergovernmental Committee on Intellectual Property and Genetic Resources, Traditional Knowledge and Folklore, and the other WIPO resources available online: www.wipo.int/tk/en/tk/ including the WIPO Alternative Dispute Resolution (ADR) for Biodiversity (www.wipo.int/amc/en/center/specific-sectors/biodiversity/). 
property, and measures to secure the ownership and control of this traditional knowledge by local and traditional communities and indigenous peoples. ${ }^{39}$

\subsection{THE IMPORTANCE OF CRITICAL THINKING AND HUMAN RIGHTS} IN KNOWLEDGE PRODUCTION

This chapter began by asking what science actually is and what role it should play in mediating our global society. In its concluding paragraphs, we hope to draw the preceding threads together to begin answering those questions. What then is the added value of a human rights approach to this idea of science and its role? Equality is key. A diversity of input is essential. Decolonization of knowledge is fundamental. What science's role in society should be cannot be answered without reference to who has control over it, who decides what is or is not "scientific" research, and how its best methodologies are determined.

We build an idea of the role science ought to play by drawing on international legal instruments such as General Comments, particularly the CESCR's General Comment 25, and other UN documents, in particular the 2017 UNESCO Recommendation on Science and Scientific Researchers. ${ }^{+}$That idea focuses mainly on empirical science, that which can be tested and refuted, but also includes knowledge from diverse sources, including traditional knowledge. It requires that we apply to knowledge a degree of critical thinking. It requires the understanding that such knowledge may one day be proved wrong, or no longer apply, and that this, in itself, is deeply valuable. Even local communities, who have stewarded traditional knowledge from one generation to the next, may benefit from a university or similar institution doing further research. Their own knowledge is then tested and refuted or confirmed, but in either case it is built upon. Traditional knowledge may not be derived from the same rigorous principles as those that govern the practice of scientific research, but it has an important place in our reservoir of knowledge. Such communities may have explanations for phenomena that may at first seem rooted in superstition or ritual but often are based on invaluable lived experimentation. We must accept that the conceptualization of knowledge derives from different perspectives on the world - and that nevertheless each can contribute precious knowledge.

The progress of science and access to its benefits means different things to different groups, cultures, and societies. An understanding of science and what it should do, will be very different for the agricultural industry than it will be for the individual farmer, although they may share concerns about seeds and productivity. It will be more different still for younger people in the digital age, than for those of us who remember a time before information and communication technology, or before the Internet and social media.

39 Committee on Economic, Social and Cultural Rights, General Comment No. 25 (n. 2) para. 39.

40 Records of the General Conference, 39th session, Paris, October, 30-November 14, 2017, v. 1: Annex II (https://unesdoc.unesco.org/ark:/48223/pfooooz60889.page=116). 
We have highlighted the importance of participation in science, whether this relates to participation in research, or to access to the benefits of that research, be it through an end product or the furtherance of future research. But this also includes participation in decision-making about how science ought to contribute to society. Science has the capacity not just to contribute through end products and usages, but also through knowledge and education. It contributes a particular way of critical thinking which is valuable as a methodology for approaching all the vast and sometimes chaotic information we are confronted with in the digital age. ${ }^{41}$ As the Committee puts it in General Comment 25: "doing science does not only concern scientific professionals but also includes 'citizen science' (ordinary people doing science) and the dissemination of scientific knowledge. State Parties should not only refrain from preventing citizen participation in scientific activities but should actively facilitate it."

However, in the digital age, as technology progresses at an ever-accelerating pace, expertise has become even more indispensable. It is impossible for ordinary people to be even reasonably cognizant of all the technological advancements taking place at a given moment in their own society, much less be knowledgeable enough to make informed decisions about economic, political, social, and ethical considerations concerning those developments. By definition, there is a necessity, when considering what participation in science actually means, and therefore in the decision-making processes that govern how it mediates our individual and collective societies, to take into account the wide diversity of contributions that individuals in a society are capable of making. We suggest viewing participation as a continuum on which all contributions can be seen, analyzed, and made use of..$^{42}$ Public consultations can be valuable, and are made easier by ICT in the networked, digital age, but the extent to which even a well-educated public can valuably contribute to informed policy and decision-making processes is debatable. ${ }^{43}$ Yet, to discount such participation would be undemocratic and undermine the political ideologies of most developed States.

\subsection{INTERDISCIPLINARY RELATIONSHIPS ALLOW DIVERSITY WITHIN DISCOURSES}

A further complication exists among even those who are experts in a given field: specialism. Few experts in technology fields are experts in the entirety of that field. Gone are the days when science commentators could usefully comment on the detail of

${ }^{41}$ On which see, for example, Mark Andrejevic, Infoglut: How Too Much Information Is Changing the Way We Think and Know (Routledge, 2013).

$4^{2}$ We are grateful to Sebastian Porsdam-Mann whose questions on this area during the original interview, and comments on this draft, have been instrumental in framing and driving this idea.

43 An entire field has arisen that critically engages with the relationship between science and technology and society, led by scholars such as Bruno Latour, Langdon Winner, Donna Haraway, and Sheila Jasanoff. See Sheila Jasanoff, "A Field of Its Own: The Emergence of Science and Technology Studies," in Robert Froderman (ed.), The Oxford Handbook of Interdisciplinarity (Oxford University Press, 2017). 
a given scientific or technological discipline. An expert in particle physics may have something useful to say on the generality of artificial intelligence and the ethics of its various applications, but this is quite probably where their contribution would end. That same expert might have even less to say on the issues relating to biomedical research. So, how do we ensure the opportunity for participation from everyone in a meaningful way?

It begins with transparency, and progresses to valuable contributions through education - popular and life-long education about what emergent technologies actually involve and what the ethical debates surrounding their use really mean. Only a small cadre of experts in a given field understand its applications, but even they are not experts in how those applications might impact society in the short, medium, and long terms. It is not only human rights scholars and practitioners who express concern about those in the technology industries dictating how human rights will apply to the myriad applications of their technological innovations - many in the technology industries themselves accept they should not be making those kinds of decisions. One key example is content moderation by Internet platforms. The frameworks applied by the platforms to govern speech on their networks only approximates human rights norms, and very often, given the US-centric approach, is informed only by the First Amendment to the US Constitution, rather than by regional and international human rights instruments and jurisprudence. ${ }^{44} \mathrm{~A}$ framework already exists, but it is not the framework platforms are using to regulate speech in the principal environment in which speech now takes place. ${ }^{45}$ This conflict cannot continue and can only be resolved through interdisciplinary approaches that necessitate conversations and cooperation between specialists in disparate areas.

Commercial incentives driving innovation, and therefore the practice of scientific research, must not ignore fundamental human rights principles. The right to science necessarily influences and supports in a cross-cutting way the application of science and technology, and discussion of the ethics of both, to many other human rights. Experimentation in the behavioral and neurosciences, for example, where consultation and consent are in issue because a private entity conducts the research rather than one is that is publicly funded and therefore subject to different legal scrutiny, identifies a lacuna that is becoming more pervasive and dangerous. Potential harms ought to be identified and debated, and here again transparency is key. Trade secrets have, for too long, made the products of scientific research opaque and unaccountable. This problem, as we have already identified, is significant in the area of bias in algorithms. Related to this, in the criminal law context, algorithms currently assist law enforcement and courts in ways that are almost entirely opaque and therefore unknowable to the subjects of those investigations and court

44 Klonick, "The New Governors: The People, Rules, and Processes Governing Online Speech" (n. 10); Cohen, "The Zombie First Amendment," and Balkin, "Free Speech in the Algorithmic Society: Big Data, Private Governance, and New School Speech Regulation" (n. 16).

45 David Kaye (n 15) and Evelyn Mary Aswad, "To Protect Freedom of Expression, Why Not Steal Victory from the Jaws of Defeat?" (2020) 77 Wash. \& Lee L. Rev. 6o9. 
proceedings. ${ }^{4}$ Independent oversight structured so as to protect trade secrets is possible, but technology innovators resist it. The balance towards commercial interests at the expense of human rights and notions of natural justice and due process has leaned too heavily the wrong way for too long. Commercial entities have greater resources and influence and have used that to unbalance the field in their favor. They are not accountable to the human rights system, nor do they sufficiently participate or engage with it. ${ }^{47}$ In fact, they are beginning to claim false legitimacy from the language of human rights without being properly bound by its norms. This must change.

Another way in which the difficulties inherent in participation as a result of barriers imposed by specialist expertise may be addressed is through the formation of interdisciplinary groups and organizations whose debates and cooperation take advantage of diverse viewpoints and expertise. These can be both formal and informally constituted, but they must include stakeholders for a wide variety of interested, but appropriately qualified groups; from private industry as well as the public sphere. In all of the consultations and meetings preceding the Patent and Copyright reports to the UN in 2015, where anything relevant to intellectual property was to be discussed or that might conceivably have relevant implications, WIPO was present. Yet those representatives from WIPO who attended seemed to be isolated within the wider organization. While they themselves were responsive, their institution did not necessarily speak with a unified voice or a unified narrative. Private law and public law conversations must overlap, particularly those having human rights implications. Here again, culture intersects with science and cultural rights inform how the right to science, and participation in science in all the guises we have discussed, must be interpreted.

In the ICT arena, given the transnational nature of Internet platforms and networked communication and interaction, such interdisciplinary and international collaboration gains greater significance. We have identified a problematic divide between the way human rights have traditionally mediated the relationship between the individual and the State, but not between the individual and private entities. Yet private entities, even those with purely commercial incentives, can and should play an important role in facilitating this relationship. Such actors have changed the appearance of the rights landscape, and human rights thinking will need to adapt as a consequence. Human rights scholars and practitioners must find like-minded allies in the private arena. Until we actually come together in discussions on issues that impact law and policy, it doesn't matter what guiding principles we may have for businesses. These are not binding instruments, so we must always be keen to have further conversations in order to actually make rights collaboration a reality on the ground. CESCR has said very clearly that the State where an individual is a citizen has responsibilities, duties, and obligations in respect of rights, but that in reality it doesn't always work that way. Private entities, particularly influential nonstate actors

$4^{6}$ For an excellent summary and analysis of the key debates in this area, see Sonia K. Katyal, "Private Accountability in the Age of Artificial Intelligence" (2019) 66 UCLA L. Rev. 54.

47 Evelyn Douek, "The Limits of International Law in Content Moderation" (2020) UCI Journal of International, Transnational, and Comparative Law (Forthcoming) (https://ssrn.com/ abstract $=3709566$ or http: //dx.doi.org/10.2139/ssm. 3709566). 
like Internet platforms, actually have, we believe, a part to play in removing lacunae and ensuring compliance with rights.

\subsection{CONCLUDING REMARKS}

It remains to be seen what impact the CESCR's General Comment 25 will have, but it seems clear it is a stepping stone to something else; the opening of a door to a more complex, nuanced debate and, perhaps, a renewed importance for the right to science, and an evolving role in the protection of other human rights. It highlights, we believe, the need for (1) a broader perspective on the right to science, and (2) concrete mechanisms for giving effect to its core principles outside of human rights law. One clear statement it makes is to emphasize the symbiotic relationship between the right to science and cultural rights. We repeat the following: "Cultural life is an inclusive concept encompassing all manifestations of human existence' ... Thus, the right of everyone to take part in cultural life includes the right of every person to take part in scientific progress and in decisions concerning its direction."

For the justiciability of the right to science to become a reality, we must recognize that the modern landscape of rights and technology is complex and nuanced, and raises many unknowns. A useful approach might be to pick perhaps one or two discrete areas of concern in order to determine what it is that can really be done and which would allow a certain balance to be achieved, rather than attempting to solve the whole problem at once. Collaboration, as envisaged by the drafters of the UDHR and as required now in the interdisciplinary contexts we believe are necessary, involves steep learning curves for all involved, and a willingness to step out of comfort zones and be vulnerable. All involved will be characterized by their own compulsions and obligations, whether they are representatives of a State's executive organs and institutions, or human rights practitioners and scholars, or those with private commercial interests. We must attempt to understand each other's interests and obligations, and see the discourse from the perspective of those on the opposite side.

Science can and should be common ground; a way of thinking and approaching the problems critically, but also a means by which knowledge production and serendipity can be optimized. Academics from different disciplines, who are steeped in those scientific ideals of testing and refuting, are one way in which that interactive discourse can be facilitated. Perhaps most importantly, in the digital age, is the need for technology professionals and technology industry representatives, particularly those with some influence within their organizations as well as independent experts, to be present and to engage fully and openly. And while it would be valuable to have some of these groups formally discussing these areas under the auspices of international organizations like the UN and UNESCO, through the Office of the High Commissioner for Human Rights (OHCHR) and the principal treaty bodies, it is important given how swiftly technology moves, to have adaptable frameworks for discourse and informal policy advice that is truly interdisciplinary and diverse. 